\title{
Impact of overweight on left ventricular function in type 2 diabetes mellitus
}

\author{
Makiko Suto ${ }^{1}$, Hidekazu Tanaka ${ }^{1 *}$, Yasuhide Mochizuki', Jun Mukai ${ }^{1}$, Hiroki Takada', Fumitaka Soga', \\ Kumiko Dokuni ${ }^{1}$, Yutaka Hatani ${ }^{1}$, Keiko Hatazawa ${ }^{1}$, Hiroki Matsuzoe ${ }^{1}$, Hiroyuki Sano ${ }^{1}$, Hiroyuki Shimoura ${ }^{1}$, \\ Junichi Ooka', Kensuke Matsumoto' ${ }^{1}$, Yushi Hirota ${ }^{2}$, Wataru Ogawa ${ }^{2}$ and Ken-ichi Hirata ${ }^{1}$
}

\begin{abstract}
Background: Coexistence of left ventricular (LV) longitudinal myocardial systolic dysfunction with LV diastolic dysfunction could lead to heart failure with preserved ejection fraction (HFpEF). Diabetes mellitus (DM) is known as a significant factor associated with HFpEF. Although the mechanisms of DM-related LV myocardial injury are complex, it has been postulated that overweight contributes to the development of LV myocardial injury in type 2 diabetes mellitus (T2DM) patients. However, the precise impact of overweight on LV longitudinal myocardial systolic function in T2DM patients remains unclear.
\end{abstract}

Methods: We studied 145 asymptomatic T2DM patients with preserved LV ejection fraction (LVEF) without coronary artery disease. LV longitudinal myocardial systolic function was assessed by global longitudinal strain (GLS), which was defined as the average peak strain of 18-segments obtained from standard apical views. Overweight was defined as body mass index $(\mathrm{BMI}) \geq 25 \mathrm{~kg} / \mathrm{m}^{2}$. Ninety age-, gender- and LVEF-matched healthy volunteers served as controls.

Results: GLS of overweight T2DM patients was significantly lower than that of non-overweight patients $(17.9 \pm 2.4 \%$ vs. $18.9 \pm 2.6 \%, \mathrm{p}<0.05)$, whereas GLS of both overweight and non-overweight controls was similar $(19.8 \pm 1.3 \%$ vs. $20.4 \pm 2.1 \%, p=0.38$ ). Furthermore, multiple regression analysis revealed that for T2DM patients, BMI was the independent determinant parameters for GLS as well as LV mass index.

Conclusions: Overweight has a greater effect on LV longitudinal myocardial systolic function in T2DM patients than on that in non-DM healthy subjects. Our finding further suggests that the strict control of overweight in T2DM patients may be associated with prevention of the development of HFpEF.

Keywords: Diabetes mellitus, Left ventricular longitudinal function, Left ventricular diastolic function, Obesity

\section{Introduction}

Heart failure (HF) with preserved ejection fraction ( $\mathrm{HFpEF}$ ), which is determined as the presence of $\mathrm{HF}$ symptoms and signs with left ventricular ejection fraction (LVEF) $\geq 50 \%$ [1], currently accounts for roughly half of all HF cases and its prevalence is related to HF with reduced ejection fraction (HFrEF). Patients with HFpEF usually are of advanced age and predominantly women with multiple comorbidities [2, 3], and diabetes

\footnotetext{
*Correspondence: tanakah@med.kobe-u.ac.jp

${ }^{1}$ Division of Cardiovascular Medicine, Department of Internal Medicine, Kobe University Graduate School of Medicine, 7-5-2, Kusunoki-cho, Chuo-ku, Kobe 650-0017, Japan

Full list of author information is available at the end of the article
}

mellitus (DM) is considered a major cause of HFpEF, accounting for $20-45 \%$ of all cases [4]. DM-related cardiac dysfunction is currently defined as a form of LV diastolic dysfunction, and several studies of DM patients have identified LV diastolic dysfunction as the earliest functional alteration in the course of diabetic cardiomyopathy [5-8], which could lead to the development of HFpEF. On the other hand, LV longitudinal myocardial systolic dysfunction has been identified in DM patients with preserved LVEF but without overt coronary artery disease or HF [9-16], and some investigators reported that it may be considered the first marker of a preclinical form of DM-related cardiac dysfunction in such patients $[9,17]$. Thus, LV longitudinal myocardial systolic 
dysfunction may coexist with LV diastolic dysfunction in patients with DM and lead to HFpEF. It has been demonstrated that overweight is also an important cause of HFpEF as well as DM, with more than $80 \%$ of patients with HFpEF being overweight [18]. In addition, it has been postulated that overweight contributes to the development of LV myocardial injury in DM patients, but the precise impact of overweight on LV function is not yet fully understood. The aim of this study was thus to investigate the effect of overweight on LV longitudinal myocardial systolic function in asymptomatic patients with type 2 DM (T2DM) with preserved LVEF but without coronary artery disease.

\section{Methods}

\section{Study population}

Between July 2013 and September 2015, 155 asymptomatic T2DM patients admitted to Kobe University Hospital were prospectively enrolled in this study. Patients were excluded from enrolment study if they met any of the following criteria: (1) previous or current history of HF; (2) previous history or suspicion of coronary artery disease; (3) LVEF < 55\%; (4) previous history of openheart surgery and congenital heart disease; (5) serious renal dysfunction defined as glomerular filtration rate $<30 \mathrm{~mL} / \mathrm{min} / 1.73 \mathrm{~m}^{2}$; (6) uncontrolled hypertension > 180/100 mmHg; (7) more than moderate valvular heart disease; and (8) atrial fibrillation. All patients underwent exercise stress or pharmacological testing such as treadmill exercise or stress myocardial perfusion scintigraphy $>2$ weeks after admission, and none of them showed an ischemic response. The diagnosis of T2DM was based on the World Health Organization criteria [19]. For comparison, a control group randomly taken from our database by the observers who have no involvement in echocardiographic analysis to have a similar age, gender and LVEF distribution, and consisting of 90 subjects without a history of DM or other cardiovascular disease. This study was approved by the local ethics committee of our institution (No. 160205).

\section{Echocardiographic examination}

All patients underwent a resting standard echocardiographic examination less than 2 weeks after admission by means of a $3.5 \mathrm{MHz}$ transducer on a single commercially available echocardiographic system (Vivid E9; General Electric Medical Systems, Milwaukee, WI). Digital routine grayscale two-dimensional cine loops from three consecutive heart beats were obtained at end-expiratory apnea from standard parasternal and apical views used for speckle-tracking strain analysis. Sector width was optimized to allow complete myocardial visualization while maximizing the frame rate. Standard echocardiographic measurements were obtained according to the current guidelines of the American society of echocardiography/European association of cardiovascular imaging [20]. Conventional LV diastolic function was also evaluated based on current guidelines [21].

\section{LV speckle-tracking strain analysis}

Two-dimensional speckle-tracking strain analysis was semi-automatically performed with dedicated software (EchoPAC version 113; General Electric Medical Systems). Briefly, the first region of interest was manually traced with the point-and-click approach on the endocardium of LV at the end-systole phase. The second larger region of interest was then generated outside and carefully adjusted near the epicardium. Finally, six strain segments and corresponding time-strain curves were generated. We used the onset point of the QRS complex as a reference for LV strain analysis. Global longitudinal strain (GLS) was then determined as the averaged peak strain from three standard apical views in accordance with current guidelines (Fig. 1) [20], which also recommend expressing all strain values as absolute values, as was done in our study, to avoid confusion about magnitude relationships.

\section{Clinical data for T2DM patients}

Dyslipidemia was defined as fasting low-density lipoprotein $\geq 140 \mathrm{mg} / \mathrm{dL}$, or current use of anti-dyslipidemia drugs [22]. Blood pressure was obtained simultaneously with transthoracic echocardiography. Hypertension was then defined as systolic blood pressure $\geq 140 \mathrm{mmHg}$ or diastolic blood pressure $\geq 90 \mathrm{mmHg}$, or current treatment with anti-hypertensive agents [23]. Overweight was defined in accordance with the World Health Organization's definition as body mass index (BMI) $\geq 25 \mathrm{~kg} / \mathrm{m}^{2}$.

\section{Statistical analysis}

Continuous variables were expressed as mean values $\pm \mathrm{SD}$, while categorical data were summarized as frequencies and percentages. The parameters of the two subgroups were compared by using the unpaired t test, which was also used for comparison of continuous variables. Proportional differences were evaluated with the Chi square test and Fisher's exact test. Independent associations of GLS with clinical and echocardiographic parameters in T2DM patients were evaluated by means of multiple regression analysis. The confounding factors for multiple regression analysis were based on the associated factors with subclinical LV dysfunctions in DM patients with preserved LVEF which were previously reported [14, 15, 24]. Statistical significance for each step was basically defined as $\mathrm{p}$ value $<0.05$. All the analyses were performed with commercially available software 


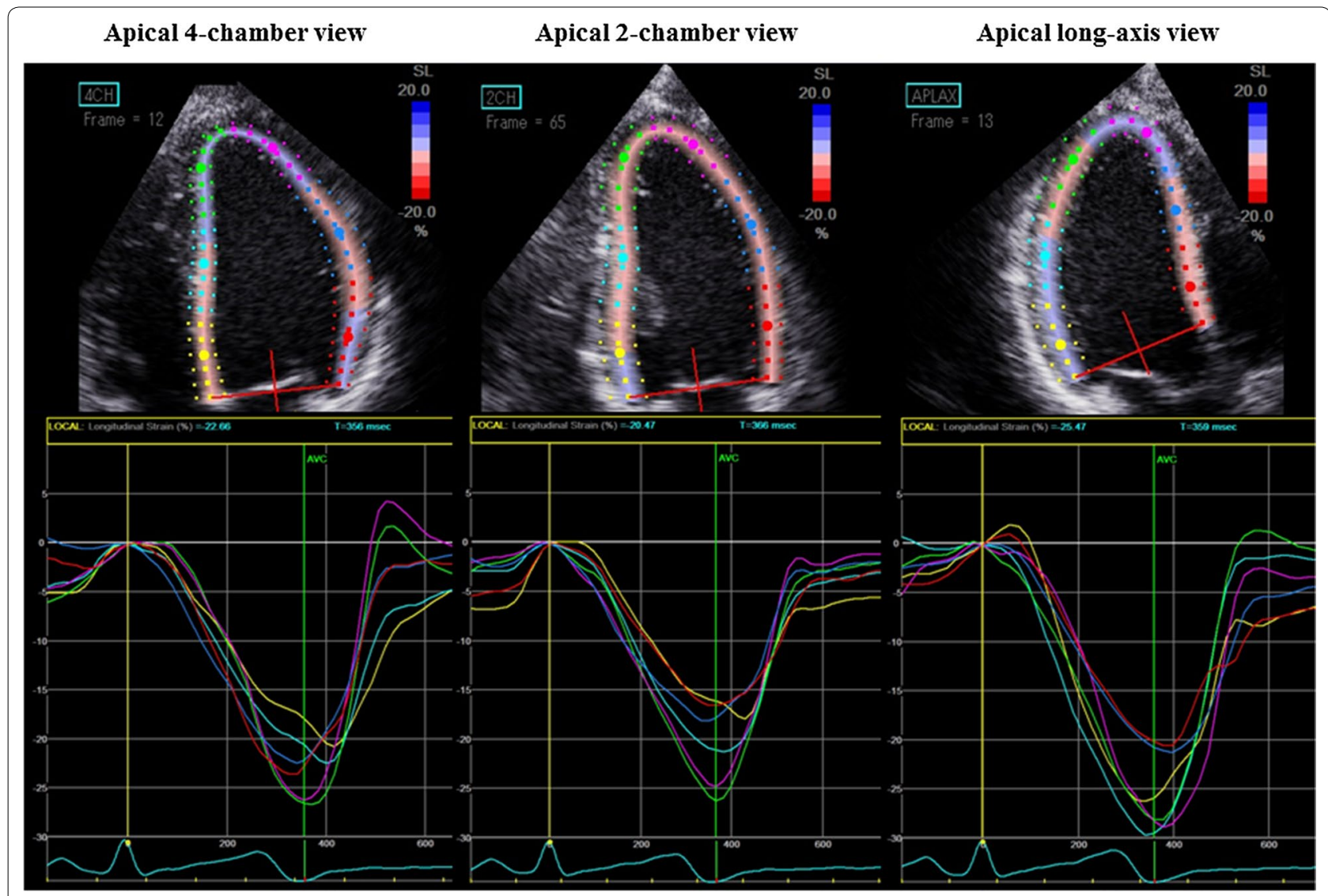

Fig. 1 Example of a color-coded two-dimensional display of the left ventricle (LV) and corresponding time-strain curves from $18 \mathrm{LV}$ sites derived from the three standard apical views for measurement of global longitudinal strain (GLS). GLS was determined as the average peak strain of 18 LV segments, and was expressed as an absolute value

(MedCalc software version 15.11.4; MedCalc Software, Mariakerke, Belgium).

\section{Results}

Baseline characteristics of T2DM patients and controls

Of the total of 155 T2DM patients enrolled in this study, 10 patients $(6 \%)$ were excluded from all subsequent analyses because of suboptimal quality of echocardiographic images, so that the final study population consisted of 145 T2DM patients. The baseline characteristics of the latter and the 90 controls are summarized in Table 1 . Clinical data showed that patients with T2DM were more likely to have higher BMI and heart rate, while echocardiographic data showed they were more likely to have a smaller stroke volume and GLS, and a larger left atrial volume index, LV mass index and E/e'. Table 2 shows the baseline characteristics of the T2DM patients with and without overweight. Overweight, defined as BMI $\geq 25 \mathrm{~kg} / \mathrm{m}^{2}$, was detected in 75 T2DM patients (52\%), and the remaining 70 (48\%) were classified as T2DM patients without overweight. Clinical data showed that the prevalence of dyslipidemia in T2DM patients with overweight was higher than in those without overweight, while echocardiographic data showed that T2DM patients with overweight had a higher LV mass index and lower GLS compared to those without overweight. Intra- and interobserver reproducibility for GLS for DM patients in our study group was previously reported [14-16, 24].

Effect of overweight on LV longitudinal myocardial systolic function in T2DM patients

LV longitudinal myocardial systolic function as assessed in terms of GLS was similar for controls with and without overweight $(19.8 \pm 1.3 \%$ vs. $20.4 \pm 2.1 \%$, p $=0.34)$, whereas GLS for T2DM patients with overweight was significantly lower than that for those without overweight $(17.9 \pm 2.4 \%$ vs. $18.9 \pm 2.6 \%, \mathrm{p}<0.05)$ (Fig. 2 ).

\section{Association of GLS with overweight in T2DM patients}

GLS significantly correlated with BMI in the case of T2DM patients, but no such significant correlation was observed in controls (Fig. 3). Table 3 shows the results 
Table 1 Baseline characteristics of normal controls and T2DM patients

\begin{tabular}{|c|c|c|c|}
\hline & $\begin{array}{l}\text { Controls } \\
(n=90)\end{array}$ & $\begin{array}{l}\text { T2DM patients } \\
(n=145)\end{array}$ & $p$ value \\
\hline \multicolumn{4}{|l|}{ Clinical data } \\
\hline Age, years & $57 \pm 15$ & $60 \pm 13$ & 0.08 \\
\hline Female, n (\%) & $50(56)$ & $67(46)$ & 0.16 \\
\hline Body mass index, $\mathrm{kg} / \mathrm{m}^{2}$ & $22.0 \pm 3.9$ & $25.4 \pm 5.0$ & $<0.05$ \\
\hline $\begin{array}{l}\text { Body mass index } \geq 25 \mathrm{~kg} / \mathrm{m}^{2} \text {, } \\
\mathrm{n}(\%)\end{array}$ & $14(16)$ & $70(48)$ & $<0.05$ \\
\hline $\begin{array}{l}\text { Body mass index } \geq 30 \mathrm{~kg} / \mathrm{m}^{2}, \\
\mathrm{n}(\%)\end{array}$ & $3(3)$ & $27(19)$ & $<0.05$ \\
\hline Systolic blood pressure, $\mathrm{mmHg}$ & $122 \pm 14$ & $129 \pm 20$ & $<0.05$ \\
\hline $\begin{array}{l}\text { Diastolic blood pressure, } \\
\mathrm{mmHg}\end{array}$ & $72 \pm 11$ & $74 \pm 12$ & 0.27 \\
\hline Heart rate, bpm & $67 \pm 11$ & $75 \pm 12$ & $<0.05$ \\
\hline \multicolumn{4}{|l|}{ Echocardiography } \\
\hline LV end systolic volume, mL & $26 \pm 9$ & $26 \pm 10$ & 0.82 \\
\hline LV end diastolic volume, $\mathrm{mL}$ & $74 \pm 22$ & $75 \pm 21$ & 0.68 \\
\hline LV ejection fraction, \% & $66 \pm 5$ & $66 \pm 5$ & 0.93 \\
\hline Stroke volume, $\mathrm{mL}$ & $67 \pm 14$ & $63 \pm 13$ & $<0.05$ \\
\hline Left atrial volume index, $\mathrm{mL} / \mathrm{m}^{2}$ & $26 \pm 9$ & $30 \pm 9$ & $<0.05$ \\
\hline LV mass index, $\mathrm{g} / \mathrm{m}^{2}$ & $71 \pm 19$ & $79 \pm 21$ & $<0.05$ \\
\hline$E / e^{\prime}$ & $8.4 \pm 2.5$ & $10.7 \pm 4.0$ & $<0.05$ \\
\hline$e^{\prime}$ & $9.0 \pm 3.1$ & $6.0 \pm 1.6$ & $<0.01$ \\
\hline Global longitudinal strain, \% & $20.3 \pm 2.0$ & $18.0 \pm 2.6$ & $<0.05$ \\
\hline
\end{tabular}

Values are mean \pm SD for normally distributed data and median and interquartile range for non-normally distributed data, or $\mathrm{n}(\%)$

$D M$ diabetes mellitus, $L V$ left ventricular, $E$ peak early diastolic mitral flow velocity, $e^{\prime}$ spectral pulsed-wave Doppler-derived early diastolic velocity from the septal mitral annulus

of the multiple regression analysis for the association of GLS with clinical and echocardiographic parameters for T2DM patients. An important finding of the multiple regression analysis was that BMI in the case of T2DM patients was the independent determinant parameters for GLS as well as LV volume index.

\section{Discussion}

The findings of the present study indicate that LV longitudinal myocardial systolic function in T2DM patients with overweight was significantly worse than that in T2DM patients without overweight, whereas, no such finding was obtained for age-, gender-, and LVEF-matched controls. In addition, BMI was the independent determinant parameters for GLS for T2DM patients.

\section{Association of DM-related cardiac dysfunction with HFpEF} HFpEF, which clinically presents as LV diastolic dysfunction, currently accounts for roughly half of all HF cases and its prevalence relative to HFrEF continues to rise at an alarming rate of $1 \%$ per year [25]. Patients with $\mathrm{HFpEF}$ has similar risk of rate of rehospitalization and mortality as those with HFrEF, which was $5-20$ and $3-9 \%$ at 30 days, respectively [26, 27]. Patients with HFpEF usually are of advanced age and predominantly women with multiple comorbidities such as hypertension, DM, overweight/obesity, coronary artery disease, atrial fibrillation, hyperlipidemia, renal insufficiency, and sleep apnea $[2,3]$. Of these comorbidities, DM is considered a major cause of HFpEF with a prevalence of $20-45 \%$ [4]. Thus, DM-related cardiac dysfunction is currently defined as a form of LV diastolic dysfunction, and several studies of DM patients have identified LV diastolic dysfunction as the earliest functional alteration in the course of diabetic cardiomyopathy [5-7], resulting in its establishment as an important prognostic parameter [6]. In fact, LV diastolic dysfunction has been reported as present in 23 to $75 \%$ of patients with DM $[6,28,29]$.

LV longitudinal myocardial systolic dysfunction, on the other hand, as assessed in terms of lower GLS, has been identified in DM patients with preserved LVEF and without overt coronary artery disease or HF [9-16]. Nakai et al. [10] reported that GLS in DM patients was significantly lower than that in age-matched normal subjects in spite of similar LVEF, and 43\% of DM patients showed LV longitudinal myocardial systolic dysfunction detected as GLS $<17.2 \%$. In addition, Ernande et al. [12] showed that $23 \%$ of T2DM patients with preserved LVEF had LV longitudinal myocardial systolic dysfunction detected as GLS $<18 \%$. Our group recently demonstrated that, in contrast to age-related LV diastolic dysfunction in normal subjects, LV diastolic function was associated with LV longitudinal myocardial systolic function independently of age in asymptomatic DM patients with preserved LVEF and without coronary artery disease [24]. In addition, recent investigators have maintained that LV longitudinal myocardial systolic dysfunction, rather than LV diastolic dysfunction, may be considered as the first marker of a preclinical form of DM-related cardiac dysfunction in DM patients with preserved LVEF and without overt HF $[9,17]$. Ernande et al. further showed that LV longitudinal myocardial systolic dysfunction detected as GLS $<18 \%$ was present even in T2DM patients with preserved LVEF and normal LV diastolic function [9]. In addition, our group recently showed that GLS was a strong determinative factor for $\mathrm{e}^{\prime}$ and $\mathrm{E} / \mathrm{e}^{\prime}$ independent of age or other clinical factors in 177 asymptomatic DM patients with preserved LVEF [24].

Overweight/obesity and LV diastolic function and HFpEF Multiple studies have established overweight/obesity as a risk factor for the development of HF. Moreover, recent studies have shown that $29-40 \%$ of patients with HF are overweight and $30-49 \%$ are obese, with a significantly 
Table 2 Baseline characteristics of T2DM patients with and without overweight

\begin{tabular}{|c|c|c|c|}
\hline & $\begin{array}{l}\text { T2DM patients with overweight } \\
(\mathrm{n}=70)\end{array}$ & $\begin{array}{l}\text { T2DM patients without overweight } \\
(n=75)\end{array}$ & $p$ value \\
\hline \multicolumn{4}{|l|}{ Clinical data } \\
\hline Age, years & $59 \pm 14$ & $61 \pm 13$ & 0.31 \\
\hline Female, n (\%) & $36(51)$ & $31(41)$ & 0.22 \\
\hline Body mass index, $\mathrm{kg} / \mathrm{m}^{2}$ & $30 \pm 4$ & $22 \pm 2$ & $<0.05$ \\
\hline Heart rate, bpm & $72 \pm 13$ & $70 \pm 11$ & 0.25 \\
\hline DM duration, years & $12 \pm 8$ & $10 \pm 10$ & 0.31 \\
\hline Hypertension, n (\%) & $46(66)$ & $39(53)$ & 0.11 \\
\hline Dyslipidemia, n (\%) & $55(79)$ & $35(47)$ & $<0.05$ \\
\hline \multicolumn{4}{|l|}{ Blood exam and urinary test } \\
\hline $\mathrm{HbA} 1 \mathrm{c}, \%$ & $8.5 \pm 1.6$ & $8.7 \pm 2.5$ & 0.53 \\
\hline Low-density lipoprotein, mg/dL & $107 \pm 31$ & $110 \pm 37$ & 0.52 \\
\hline Triglyceride, mg/dl & $165 \pm 75$ & $138 \pm 89$ & $<0.05$ \\
\hline $\mathrm{eGFR}, \mathrm{mL} / \mathrm{min} / 1.73 \mathrm{~m}^{2}$ & $72 \pm 24$ & $77 \pm 26$ & 0.24 \\
\hline \multicolumn{4}{|l|}{ Medical treatment } \\
\hline$C C B, n(\%)$ & $33(47)$ & $15(20)$ & $<0.05$ \\
\hline ACEI/ARB, n (\%) & $41(59)$ & $30(41)$ & $<0.05$ \\
\hline$\beta$-Blocker, n (\%) & $7(10)$ & $6(8)$ & 0.78 \\
\hline Statin, n (\%) & $44(63)$ & $25(34)$ & $<0.05$ \\
\hline Insulin, n (\%) & $41(59)$ & $32(43)$ & 0.07 \\
\hline DPP-4I, n (\%) & $38(54)$ & $39(53)$ & 0.85 \\
\hline GLP-1RA, n (\%) & $12(17)$ & $2(2)$ & $<0.05$ \\
\hline Sulfonylurea, n (\%) & $18(26)$ & $18(24)$ & 0.84 \\
\hline $\mathrm{a}-\mathrm{Gl}, \mathrm{n}(\%)$ & $12(17)$ & $17(23)$ & 0.36 \\
\hline Thiazolidine, n (\%) & $10(14)$ & $4(5)$ & 0.09 \\
\hline Metformin, n (\%) & $44(63)$ & $35(47)$ & 0.06 \\
\hline \multicolumn{4}{|l|}{ Echocardiography } \\
\hline LV end systolic volume, $\mathrm{mL}$ & $28 \pm 10$ & $25 \pm 10$ & 0.08 \\
\hline LV end diastolic volume, $\mathrm{mL}$ & $78 \pm 21$ & $72 \pm 21$ & 0.13 \\
\hline LV ejection fraction, \% & $65 \pm 5$ & $66 \pm 4$ & 0.06 \\
\hline Stroke volume, $\mathrm{mL}$ & $64 \pm 14$ & $62 \pm 11$ & 0.34 \\
\hline Left atrial volume index, $\mathrm{mL} / \mathrm{m}^{2}$ & $31 \pm 9$ & $29 \pm 8$ & 0.08 \\
\hline LV mass index, $\mathrm{g} / \mathrm{m}^{2}$ & $84 \pm 19$ & $75 \pm 21$ & $<0.05$ \\
\hline$E / e^{\prime}$ & $11.1 \pm 4.0$ & $10.3 \pm 4.1$ & 0.26 \\
\hline$e^{\prime}$ & $5.8 \pm 1.4$ & $6.3 \pm 1.8$ & 0.06 \\
\hline Global longitudinal strain, \% & $17.0 \pm 2.4$ & $18.9 \pm 2.6$ & $<0.05$ \\
\hline
\end{tabular}

Values are mean $\pm S D$ for normally distributed data and median and interquartile range for non-normally distributed data, or $\mathrm{n}(\%)$

GFR estimated glomerular filtration rate, $C C B$ calcium channel blocker, $A C E l$ angiotensin-converting enzyme inhibitor, ARB angiotensin II receptor blocker, DPP-4I dipeptidyl peptidase-4 inhibitor, GLP-1RA glucagon like peptide-1 receptor agonist, $a$-Gl a-glucosidase inhibitor. Other abbreviations as in Table 1

higher prevalence of obesity for patients with HFpEF compared with patients with HFrEF [30, 31]. It has been also demonstrated that overweight/obesity is an important cause of HFpEF as well as of DM, with more than $80 \%$ of patients with HFpEF being overweight/obese [18]. Ichikawa et al. [32] reported their findings from 148 asymptomatic patients with T2DM with preserved LVEF that abdominal visceral adipose tissue as measured by computed tomography was associated with, as well as an independent determinant of, LV diastolic function. Ho et al. [33] also showed that greater BMI was associated with worse GLS in 6231 participants. They also showed that higher circulating leptin concentrations were associated with worse GLS, suggesting a potential role for circulating adipokines in obesity-related LV damage. Although the relationship between overweight/obesity and incident HF may be associated with hemodynamic and anatomic cardiac changes related to excess body 


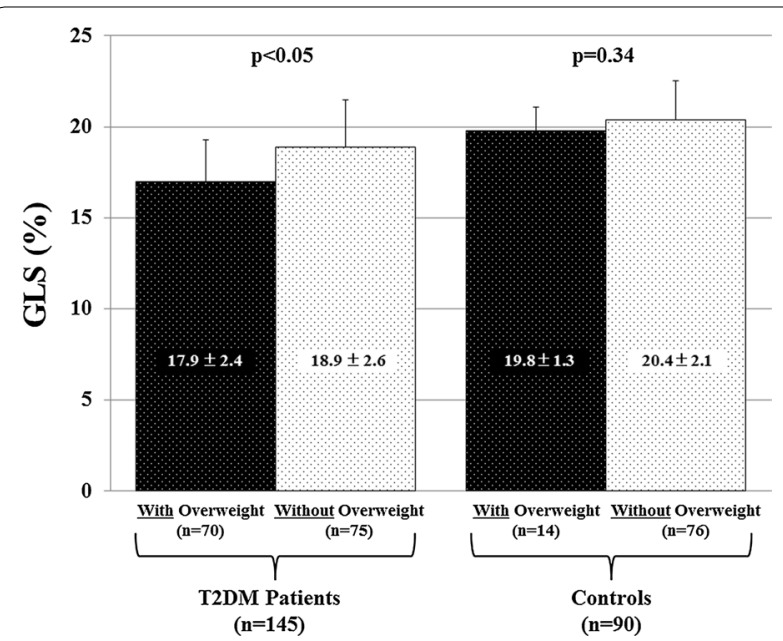

Fig. 2 Bar graphs showing comparison between global longitudinal strain (GLS) of subjects with and without overweight, showing that GLS of overweight diabetes mellitus (DM) patients is significantly lower than that of non-overweight DM patients, whereas GLS was similar for normal controls with and without overweight

mass, recent evidence suggests that the relationship is also mediated by obesity-related inflammatory response, metabolic and insulin resistance, and hormonal changes. Increased inflammatory cytokines such as interleukin-6, interleukin-8 and monocyte chemoattractant protein-1 have been shown to be significant indicators of a greater degree of HFpEF [34]. In addition, high plasma levels of tumor necrosis factor- $\alpha$ and interleukin- 6 might cause cardiac diastolic dysfunction by reducing diastolic calcium reuptake in myocytes [35].

Several investigators have reported the association of weight loss with LV diastolic function in obese patients. Karimian et al. [36] reported that weight loss was associated with a reduction in mitral inflow A-wave velocity (from $65.8 \pm 19.2 \mathrm{~cm} / \mathrm{s}$ to $57.0 \pm 16.8 \mathrm{~cm} / \mathrm{s}$ ), and an increase in E/A ratio (from $1.2 \pm 0.4$ to $1.4 \pm 0.5$ ) in 32 obese patients (BMI: $40.3 \pm 6.6 \mathrm{~kg} / \mathrm{m}^{2}$ ) who underwent a 12-week lowcalorie fasting phase of a formula die. Furthermore, in eight obese patients with T2DM (BMI: $44 \pm 9 \mathrm{~kg} / \mathrm{m}^{2}$ ) who underwent sleeve gastrectomy, GLS improved from $13.2 \pm 3.7 \%$ to $19.7 \pm 2.2 \%(\mathrm{p}<0.001)$ and $\mathrm{E} / \mathrm{e}^{\prime}$ also improved from $12 \pm 4$ to $9 \pm 3(\mathrm{p}=0.028)$ after surgery [37].

\section{Effect of overweight/obesity on LV structure}

De Jong et al. [38] used 353 patients which were grouped based on diagnosis of obesity, T2DM and hypertension, with normotensive obese patients further separated based on metabolic health. They showed that metabolically healthy normotensive obese patients exhibited relatively low risk of LV concentric remodeling and concentric hypertrophy, whereas, normotensive metabolically non-healthy obese, T2DM and obese/T2DM patients were associated with increased LV concentric remodeling. Furthermore, normotensive patients with

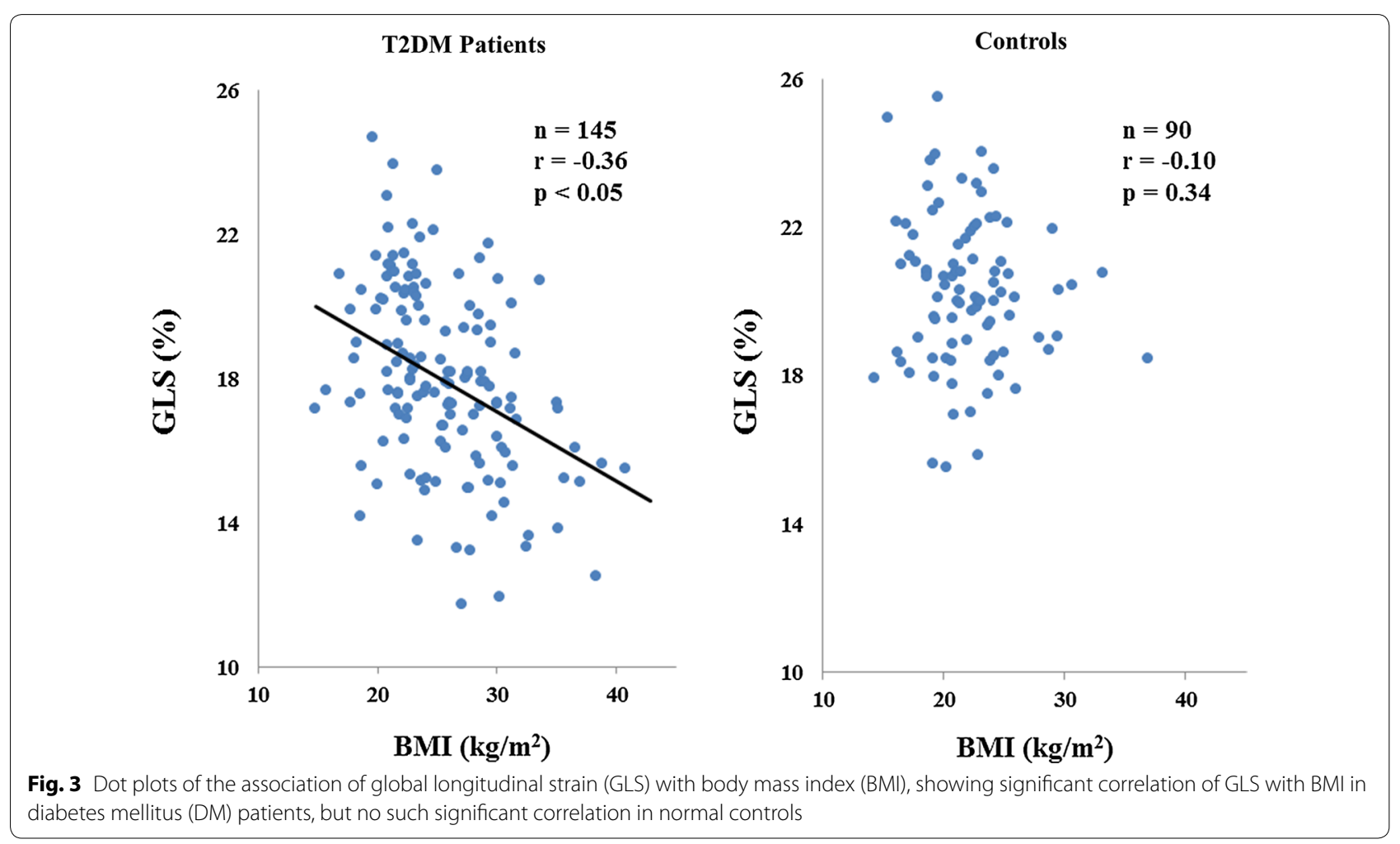


Table 3 Multiple regression analysis for GLS in T2DM patients

\begin{tabular}{lcrr}
\hline & Standardizing coefficient & t value & p value \\
\hline Age & 0.019 & 1.169 & 0.245 \\
Female & 0.144 & 0.386 & 0.700 \\
Hypertension & 0.295 & 0.705 & 0.482 \\
Dyslipidemia & 0.481 & 1.184 & 0.238 \\
HbA1C & -0.124 & -1.458 & 0.157 \\
Body mass index & -0.147 & -3.600 & $<0.001$ \\
LV mass index & -0.053 & -5.193 & $<0.001$ \\
LA volume index & -0.015 & -0.585 & 0.559 \\
\hline
\end{tabular}

$\mathrm{R}^{2}$-adjusted: 0.315

F ratio: $9.215 p<0.001$

Abbreviation as in Tables 1 and 2

both obesity and T2DM had a higher incidence of LV concentric hypertrophy and grade III LV diastolic dysfunction than normotensive patients with either condition alone. Markus et al. [39] also showed that an increase in fat mass was associated with LV concentric remodeling as well as impairment of LV diastolic functional parameters such as E/A ratio and isovolumetric relaxation time in 1189 subjects. Kishi et al. [40] reported that high insulin resistance was associated with worse relative wall thickness and worse peak longitudinal strain and early diastolic strain rate from apical 4-chamber view, and $\mathrm{e}^{\prime}$, depending on obesity level from 3179 participants. Moreover, Evin et al. [41] showed that left atrial strain as assessed by cardiac magnetic resonance imaging was a sensitive tool for the detection of early LV diastolic dysfunction in individuals with obesity and T2DM and correlated with BMI and epicardial fat. In this study, LV mass index and left atrial volume index in T2DM patients with overweight were significantly larger than those in T2DM patients without overweight $\left(79 \pm 21 \mathrm{~g} / \mathrm{m}^{2}\right.$ vs. $71 \pm 19 \mathrm{mg} / \mathrm{m}^{2}, \mathrm{p}<0.05 ; 30 \pm 9 \mathrm{~mL} / \mathrm{m}^{2}$ vs. $30 \pm 9 \mathrm{~mL} /$ $\mathrm{m}^{2}, \mathrm{p}<0.05$, respectively). On the other hand, LV mass index and left atrial volume index in controls were not different between with overweight and without overweight. $\left(69 \pm 14 \mathrm{~g} / \mathrm{m}^{2}\right.$ vs. $71 \pm 19 \mathrm{mg} / \mathrm{m}^{2}, \mathrm{p}=0.62$; $25 \pm 7 \mathrm{~mL} / \mathrm{m}^{2}$ vs. $27 \pm 9 \mathrm{~mL} / \mathrm{m}^{2}, \mathrm{p}=0.39$ ). These differences were thought to be due to the presence of LV subclinical dysfunction as assessed by lower GLS.

\section{Potential clinical implication of weight loss for T2DM patients}

Unlike findings for HFrEF, large trials testing neurohumoral inhibition have consistently failed to attain positive primary outcomes for patients with HFpEF by using, among others, angiotensin-converting enzyme inhibitors, angiotensin II receptor blockers, $\beta$-blockers and mineralocorticoid receptor antagonists, thus leading to a poor prognosis for patients with HFpEF [42]. In our study, LV diastolic function as assessed by E/e $\mathrm{e}^{\prime}$ was similar for T2DM patients, both with and without overweight $(11.1 \pm 4.0$ vs. $10.3 \pm 4.1, \mathrm{p}=0.26)$, as well as for controls with and without overweight $(8.8 \pm 2.8 \mathrm{vs}$. $8.1 \pm 2.8, \mathrm{p}=0.28$ ). These findings were thought to be due to our study population consisting of T2DM patients with asymptomatic status and without a previous history of HF. On the other hand, we were able to show that the association of overweight with LV longitudinal myocardial systolic function was stronger for T2DM patients than for non-DM patients. Moreover, BMI was identified as the independent determinant parameters for LV longitudinal myocardial systolic function in T2DM patients. As explained earlier, LV longitudinal myocardial systolic dysfunction, rather than LV diastolic dysfunction, may be considered the first marker of a preclinical form of DM-related cardiac dysfunction, and the coexistence of LV longitudinal myocardial systolic dysfunction with LV diastolic dysfunction may lead to HFpEF in asymptomatic T2DM patients with preserved LVEF. Obesity/overweight are associated with LV dysfunction and increased risk of HF and other cardiovascular diseases in even general population. However, asymptomatic patients with T2DM and preserved LVEF had impaired GLS compared to age-, gender-, and LVEF-matched non-T2DM subjects, suggesting that patients with T2DM can be particularly susceptible to harm from obesity/overweight. Our findings therefore indicate that the strict control of overweight could be associated with not only improvement of glycemic control, but also prevention of future development of HFpEF in T2DM patients, although the difference of GLS was small in this study.

\section{Study limitations}

This study was a single-center cross-sectional study, so that further longitudinal-based cohort studies are required to validate our results. Another limitation is that no long-term clinical outcome data was not available for this study. For a follow-up of this study, however, longterm clinical data is now being collected for validation of our findings through long-term follow-up studies of the associations of T2DM and overweight with the development of HFpEF in patients with T2DM patients. In addition, the blood examination in a control group such as plasma glucose or lipid data were not part of this study. Finally, the prevalence and degree of obesity in our study was mild compared to that in previous studies from Western countries. This is accounted for by the fact that many obese Asian subjects, including Japanese, show a lesser degree of adiposity than that observed in Western countries [43, 44]. However, Japanese subjects with even mild obesity tend to have obesity-related complications, 
and The Japanese Committee reported that the relative risk of negative health consequences of obesity in the groups with a BMI of $25.0-26.4$ and $26.5-29.9 \mathrm{~kg} / \mathrm{m}^{2}$ was calculated as 2.5- and 3.9-fold, respectively, of the risk of those with a BMI $<25 \mathrm{~kg} / \mathrm{m}^{2}$ [45].

\section{Conclusions}

Overweight has a greater effect on LV longitudinal myocardial systolic function in T2DM patients than on that in non-DM healthy subjects. Our finding further suggests that the strict control of overweight in T2DM patients may be associated with prevention of the development of HFpEF.

\section{Abbreviations \\ A: late diastolic atrial wave velocity; BMI: body mass index; DM: diabetes mel- litus; E: early diastolic trans-mitral flow wave velocity; e': spectral pulsed-wave Doppler-derived early diastolic velocity from the septal mitral annulus; GLS: global longitudinal strain; HF: heart failure; HFpEF: heart failure with preserved ejection fraction; HFpEF: heart failure with reduced ejection fraction; LV: left ventricular; LVEF: left ventricular ejection fraction.}

\section{Authors' contributions}

MS designed the study, carried out subject recruitment, performed echocardiography, analysed the data, and wrote the manuscript. YM, JM, HT, FS, KD, YH $\mathrm{YH}, \mathrm{HM}, \mathrm{HS}, \mathrm{HS}, \mathrm{JO}, \mathrm{KM}, \mathrm{YH}$ and WO assisted recruitment and manuscript revision. HT and HK assisted in study design, data interpretation and manuscript revision. All authors read and approved the final manuscript.

\section{Author details}

${ }^{1}$ Division of Cardiovascular Medicine, Department of Internal Medicine, Kobe University Graduate School of Medicine, 7-5-2, Kusunoki-cho, Chuo-ku, Kobe 650-0017, Japan. ${ }^{2}$ Division of Diabetes and Endocrinology, Department of Internal Medicine, Kobe University Graduate School of Medicine, Kobe, Japan.

\section{Acknowledgements}

The authors are grateful for the support of the entire staff of the Division of Diabetes and Endocrinology, Department of Internal Medicine, Kobe University Graduate School of Medicine Kobe Japan.

\section{Competing interests}

The authors declare that they have no competing interests.

\section{Availability of data and materials}

Data sharing not applicable to this article as no datasets were generated or analyzed during the current study.

\section{Consent for publication}

The consent to publish was obtained from all participants in this study.

\section{Ethics approval and consent to participate}

This study was approved by the local ethics committee of Kobe University Hospital.

\section{Funding}

The authors declare that they have no funding.

\section{Publisher's Note}

Springer Nature remains neutral with regard to jurisdictional claims in published maps and institutional affiliations.

Received: 20 September 2017 Accepted: 2 November 2017
Published online: 09 November 2017

\section{References}

1. Ponikowski P, Voors AA, Anker SD, Bueno H, Cleland JG, Coats AJ, Falk V, Gonzalez-Juanatey JR, Harjola VP, Jankowska EA, et al. 2016 ESC Guidelines for the diagnosis and treatment of acute and chronic heart failure: the task force for the diagnosis and treatment of acute and chronic heart failure of the European society of cardiology (ESC) developed with the special contribution of the heart failure association (HFA) of the ESC. Eur Heart J. 2016;37(27):2129-200.

2. Givertz MM, Slawsky MT, Moraes DL, McIntyre KM, Colucci WS. Noninvasive determination of pulmonary artery wedge pressure in patients with chronic heart failure. Am J Cardiol. 2001;87(10):1213-5.

3. Lucas C, Johnson W, Hamilton MA, Fonarow GC, Woo MA, Flavell CM, Creaser $J A$, Stevenson LW. Freedom from congestion predicts good survival despite previous class IV symptoms of heart failure. Am Heart J. 2000;140(6):840-7.

4. Dhingra A, Garg A, Kaur S, Chopra S, Batra JS, Pandey A, Chaanine AH, Agarwal SK. Epidemiology of heart failure with preserved ejection fraction. Curr Heart Fail Rep. 2014;11(4):354-65.

5. Galderisi M. Diastolic dysfunction and diabetic cardiomyopathy: evaluation by Doppler echocardiography. J Am Coll Cardiol. 2006;48(8):1548-51.

6. From AM, Scott CG, Chen HH. The development of heart failure in patients with diabetes mellitus and pre-clinical diastolic dysfunction a population-based study. J Am Coll Cardiol. 2010;55(4):300-5.

7. Poirier P, Bogaty P, Garneau C, Marois L, Dumesnil JG. Diastolic dysfunction in normotensive men with well-controlled type 2 diabetes: importance of maneuvers in echocardiographic screening for preclinical diabetic cardiomyopathy. Diabetes Care. 2001;24(1):5-10.

8. Xu B, Daimon M. Cardiac aging phenomenon and its clinical features by echocardiography. J Echocardiogr. 2016;14(4):139-45.

9. Ernande L, Bergerot C, Rietzschel ER, De Buyzere ML, Thibault H, Pignonblanc PG, Croisille P, Ovize M, Groisne L, Moulin P, et al. Diastolic dysfunction in patients with type 2 diabetes mellitus: is it really the first marker of diabetic cardiomyopathy? J Am Soc Echocardiogr. 2011;24(11):1268-75.

10. Nakai H, Takeuchi M, Nishikage T, Lang RM, Otsuji Y. Subclinical left ventricular dysfunction in asymptomatic diabetic patients assessed by two-dimensional speckle tracking echocardiography: correlation with diabetic duration. Eur J Echocardiogr. 2009;10(8):926-32.

11. Ng AC, Delgado V, Bertini M, van der Meer RW, Rijzewijk LJ, Shanks M, Nucifora G, Smit JW, Diamant M, Romijn JA, et al. Findings from left ventricular strain and strain rate imaging in asymptomatic patients with type 2 diabetes mellitus. Am J Cardiol. 2009;104(10):1398-401.

12. Ernande L, Bergerot C, Girerd N, Thibault H, Davidsen ES, Gautier Pignon-Blanc P, Amaz C, Croisille P, De Buyzere ML, Rietzschel ER, et al. Longitudinal myocardial strain alteration is associated with left ventricular remodeling in asymptomatic patients with type 2 diabetes mellitus. J Am Soc Echocardiogr. 2014;27(5):479-88.

13. Ernande L, Rietzschel ER, Bergerot C, De Buyzere ML, Schnell F, Groisne L, Ovize M, Croisille P, Moulin P, Gillebert TC, et al. Impaired myocardial radial function in asymptomatic patients with type 2 diabetes mellitus: a speckletracking imaging study. J Am Soc Echocardiogr. 2010;23(12):1266-72.

14. Mochizuki Y, Tanaka H, Matsumoto K, Sano H, Shimoura H, Ooka J, Sawa T, Ryo-Koriyama K, Hirota Y, Ogawa W, et al. Impaired mechanics of left ventriculo-atrial coupling in patients with diabetic nephropathy. Circ J. 2016;80(9):1957-64

15. Mochizuki Y, Tanaka H, Matsumoto K, Sano H, Toki H, Shimoura H, Ooka J, Sawa T, Motoji Y, Ryo K, et al. Clinical features of subclinical left ventricular systolic dysfunction in patients with diabetes mellitus. Cardiovasc Diabetol. 2015;14(1):37.

16. Mochizuki Y, Tanaka H, Matsumoto K, Sano H, Toki H, Shimoura H, Ooka J, Sawa T, Motoji Y, Ryo K, et al. Association of peripheral nerve conduction in diabetic neuropathy with subclinical left ventricular systolic dysfunction. Cardiovasc Diabetol. 2015;14(1):47.

17. Cognet T, Vervueren PL, Dercle L, Bastie D, Richaud R, Berry M, Marchal P, Gautier M, Fouilloux A, Galinier M, et al. New concept of myocardial longitudinal strain reserve assessed by a dipyridamole infusion using 2D-strain echocardiography: the impact of diabetes and age, and the prognostic value. Cardiovasc Diabetol. 2013;12:84. 
18. Haass M, Kitzman DW, Anand IS, Miller A, Zile MR, Massie BM, Carson PE. Body mass index and adverse cardiovascular outcomes in heart failure patients with preserved ejection fraction: results from the irbesartan in heart failure with preserved ejection fraction (I-PRESERVE) trial. Circ Heart Fail. 2011;4(3):324-31.

19. Boulton AJ, Gries FA, Jervell JA. Guidelines for the diagnosis and outpatient management of diabetic peripheral neuropathy. Diabet Med. 1998;15(6):508-14.

20. Lang RM, Badano LP, Mor-Avi V, Afilalo J, Armstrong A, Ernande L, Flachskampf FA, Foster E, Goldstein SA, Kuznetsova T, et al. Recommendations for cardiac chamber quantification by echocardiography in adults: an update from the American society of echocardiography and the European association of cardiovascular imaging. J Am Soc Echocardiogr. 2015;28(1):1-39.

21. Nagueh SF, Smiseth OA, Appleton CP, Byrd BF 3rd, Dokainish H, Edvardsen T, Flachskampf FA, Gillebert TC, Klein AL, Lancellotti P, et al. Recommendations for the evaluation of left ventricular diastolic function by echocardiography: an update from the American society of echocardiography and the European association of cardiovascular imaging. J Am Soc Echocardiogr. 2016;29(4):277-314.

22. Expert panel on detection $E$, treatment of high blood cholesterol in A: executive summary of the third report of the national cholesterol education program (NCEP) expert panel on detection, evaluation, and treatment of high blood cholesterol in adults (adult treatment panel III). JAMA. 2001;285(19):2486-97.

23. Calhoun DA, Jones D, Textor S, Goff DC, Murphy TP, Toto RD, White A, Cushman WC, White W, Sica D, et al. Resistant hypertension: diagnosis, evaluation, and treatment. A scientific statement from the American heart association professional education committee of the council for high blood pressure research. Hypertension. 2008;51(6):1403-19.

24. Mochizuki Y, Tanaka H, Matsumoto K, Sano H, Shimoura H, Ooka J, Sawa T, Motoji Y, Ryo-Koriyama K, Hirota Y, et al. Impact of left ventricular longitudinal functional mechanics on the progression of diastolic function in diabetes mellitus. Int J Cardiovasc Imaging. 2017. https://doi.org/10.1007/ s10554-017-1198-8.

25. Sharma GV, Woods PA, Lambrew CT, Berg CM, Pietro DA, Rocco TP, Welt FW, Sacchetti P, McIntyre KM. Evaluation of a noninvasive system for determining left ventricular filling pressure. Arch Intern Med. 2002;162(18):2084-8.

26. Nichols GA, Reynolds K, Kimes TM, Rosales AG, Chan WW. Comparison of risk of re-hospitalization, all-cause mortality, and medical care resource utilization in patients with heart failure and preserved versus reduced ejection fraction. Am J Cardiol. 2015;116(7):1088-92.

27. Cheng RK, Cox M, Neely ML, Heidenreich PA, Bhatt DL, Eapen ZJ, Hernandez AF, Butler J, Yancy CW, Fonarow GC. Outcomes in patients with heart failure with preserved, borderline, and reduced ejection fraction in the medicare population. Am Heart J. 2014;168(5):721-30.

28. Boyer JK, Thanigaraj S, Schechtman KB, Perez JE. Prevalence of ventricular diastolic dysfunction in asymptomatic, normotensive patients with diabetes mellitus. Am J Cardiol. 2004;93(7):870-5.

29. Kiencke S, Handschin R, von Dahlen R, Muser J, Brunner-Larocca HP, Schumann J, Felix B, Berneis K, Rickenbacher P. Pre-clinical diabetic cardiomyopathy: prevalence, screening, and outcome. Eur J Heart Fail. 2010;12(9):951-7.

30. Ather S, Chan W, Bozkurt B, Aguilar D, Ramasubbu K, Zachariah AA, Wehrens XH, Deswal A. Impact of noncardiac comorbidities on morbidity and mortality in a predominantly male population with heart failure and preserved versus reduced ejection fraction. J Am Coll Cardiol. 2012;59(11):998-1005.

31. Kenchaiah S, Pocock SJ, Wang D, Finn PV, Zornoff LA, Skali H, Pfeffer MA, Yusuf S, Swedberg K, Michelson EL, et al. Body mass index and prognosis in patients with chronic heart failure: insights from the candesartan in heart failure: assessment of reduction in mortality and morbidity (CHARM) program. Circulation. 2007;116(6):627-36.

32. Ichikawa R, Daimon M, Miyazaki T, Kawata T, Miyazaki S, Maruyama M, Chiang SJ, Suzuki H, Ito C, Sato F, et al. Influencing factors on cardiac structure and function beyond glycemic control in patients with type 2 diabetes mellitus. Cardiovasc Diabetol. 2013;12:38.

33. Ho JE, McCabe EL, Wang TJ, Larson MG, Levy D, Tsao C, Aragam J, Mitchell GF, Benjamin EJ, Vasan RS, et al. Cardiometabolic traits and systolic mechanics in the community. Circ Heart Fail. 2017;10(5):e003536.

34. Collier P, Watson CJ, Voon V, Phelan D, Jan A, Mak G, Martos R, Baugh JA, Ledwidge MT, McDonald KM. Can emerging biomarkers of myocardial remodelling identify asymptomatic hypertensive patients at risk for diastolic dysfunction and diastolic heart failure? Eur J Heart Fail. 2011;13(10):1087-95.

35. Zhang W, Chancey AL, Tzeng HP, Zhou Z, Lavine KJ, Gao F, Sivasubramanian N, Barger PM, Mann DL. The development of myocardial fibrosis in transgenic mice with targeted overexpression of tumor necrosis factor requires mast cell-fibroblast interactions. Circulation. 2011;124(19):2106-16.

36. Karimian S, Stein J, Bauer B, Teupe C. Improvement of impaired diastolic left ventricular function after diet-induced weight reduction in severe obesity. Diabetes Metab Syndr Obes. 2017;10:19-25.

37. Leung M, Xie M, Durmush E, Leung DY, Wong VW. Weight loss with sleeve gastrectomy in obese type 2 diabetes mellitus: impact on cardiac function. Obes Surg. 2016;26(2):321-6.

38. De Jong KA, Czeczor JK, Sithara S, McEwen K, Lopaschuk GD, Appelbe A, Cukier K, Kotowicz M, McGee SL. Obesity and type 2 diabetes have additive effects on left ventricular remodelling in normotensive patients-a cross sectional study. Cardiovasc Diabetol. 2017;16(1):21.

39. Markus MR, Werner N, Schipf S, Siewert-Markus U, Bahls M, Baumeister SE, Volzke H, Felix SB, Ittermann T, Dorr M. Changes in body weight and composition are associated with changes in left ventricular geometry and function in the general population: SHIP (study of health in pomerania). Circ Cardiovasc Imaging. 2017;10(3):e005544.

40. Kishi S, Gidding SS, Reis JP, Colangelo LA, Venkatesh BA, Armstrong AC, Isogawa A, Lewis CE, Wu C, Jacobs DR Jr, et al. Association of insulin resistance and glycemic metabolic abnormalities with $L V$ structure and function in middle age: the CARDIA study. JACC Cardiovasc Imaging. 2017;10(2):105-14.

41. Evin M, Broadhouse KM, Callaghan FM, McGrath RT, Glastras S, Kozor R, Hocking SL, Lamy J, Redheuil A, Kachenoura N, et al. Impact of obesity and epicardial fat on early left atrial dysfunction assessed by cardiac MRI strain analysis. Cardiovasc Diabetol. 2016;15(1):164.

42. Yancy CW, Jessup M, Bozkurt B, Butler J, Casey DE Jr, Colvin MM, Drazner MH, Filippatos G, Fonarow GC, Givertz MM, et al. 2016 ACC/AHA/HFSA focused update on new pharmacological therapy for heart failure: an update of the 2013 ACCF/AHA guideline for the management of heart failure: a report of the American college of cardiology/American heart association task force on clinical practice guidelines and the heart failure society of America. J Am Coll Cardiol. 2016;68(13):1476-88.

43. World Health Organization. Obesity: preventing and managing the global epidemic. Report of a WHO consultation. World Health Organ Tech Rep Ser. 2000; 894:i-xii, 1-253.

44. Yoshiike N, Matsumura Y, Zaman MM, Yamaguchi M. Descriptive epidemiology of body mass index in Japanese adults in a representative sample from the national nutrition survey 1990-1994. Int J Obes Relat Metab Disord. 1998;22(7):684-7.

45. Examination Committee of Criteria for 'Obesity Disease' in J, Japan Society for the Study of O. New criteria for 'obesity disease' in Japan. Circ J. 2002; 66(11):987-92. 